Tammam, A, Hayatleh, K, Barker, S, Ben-Esmael, M and Terzopoulos, N

Improved designs for current feedback op-amps

Tammam, A, Hayatleh, K, Barker, S, Ben-Esmael, M and Terzopoulos, N (2015) Improved designs for current feedback opamps. International Journal of Electronics Letters, 4 (2). pp. 215-227.

doi: $10.1080 / 21681724.2015 .1023366$

This version is available: https://radar.brookes.ac.uk/radar/items/6918b515-68ed-45e3-8dd8-5a66cbcbceb4/1/

Available on RADAR: July 2016

Copyright (C) and Moral Rights are retained by the author(s) and/ or other copyright owners. A copy can be downloaded for personal non-commercial research or study, without prior permission or charge. This item cannot be reproduced or quoted extensively from without first obtaining permission in writing from the copyright holder(s). The content must not be changed in any way or sold commercially in any format or medium without the formal permission of the copyright holders.

This document is the post print version of the journal article. Some differences between the published version and this version may remain and you are advised to consult the published version if you wish to cite from it. 


\title{
Improved Designs for Current Feedback Op-Amps
}

\author{
A. A. Tammam, K. Hayatleh, F.J. Lidgey, M. Ben-Esmael, N.Terzopoulos and S. Barker \\ Oxford Brookes University, Wheatley Campus, Oxford OX33 1HX, 4 UK \\ khayatleh@brookes.ac.uk
}

\begin{abstract}
The input stage design in CFOAs is primarily responsible for determining the performance of the amplifier, including CMRR [1], [2]. This paper presents the designs of two new CFOAs, one employing a cascoding technique, the other a bootstrapping technique, that provide both a high CMRR (common-mode rejection ratio) and a reduced d.c. offset voltage. Moreover, the new CFOAs design exhibits an extended high frequency bandwidth, and improved gain accuracy, enabling them to be used in applications requiring variable closed-loop gains with constant bandwidth.
\end{abstract}

Keywords: voltage-mode operational amplifier; Analogue signal processing; Current-feedback op-amp; Current mode technique; Common-mode rejection ratio; Slew-rate; Bandwidth.

\section{Introduction}

The term operational amplifier or "op-amp" refers to class of high gain DC coupled amplifier with two inputs, inverting and non-inverting, and a single output [3], [4]. The op-amp is used extensively in almost every electronic system, as it is the backbone, and the core of all fields of electronic signal processing [5], [6].

In electronic circuit design, there are many occasions where a general-purpose voltage-mode operational amplifier (VOA) is useful. If the application calls for differential inputs, high input impedance, low output impedance, high common-mode rejection ratio (CMRR), and low input referred offset voltage, the (VOA) provides a basic topology for achieving these requirements. Unfortunately, it has inherent limitations in both the gain-bandwidth trade-off and slew-rate (SR) [7], [8]. Typically, the gain-bandwidth product is a constant and the slew-rate is limited to a maximum value determined by input stage bias current [9]. The slew-rate limitations of the VOA are overcome in the alternative architecture op-amp, referred to as the current-feedback op-amp (CFOA) [10], [11]. CFOAs have been around approximately 35 years, but their popularity increased in only the last 15 years. CFOAs have greater slew rate than VOAs, thus, CFOAs are receiving increasing attention as basic building blocks in analog circuit design, and are now recognized for their excellent performance in analog signal processing [12]. CFOAs can therefore be better at solving high frequency problems than their VOA counterparts [13], [14].

Despite exhibiting excellent high frequency and high speed performance, current-feedback operational amplifiers (CFOAs) generally exhibit poor 10.1080/21681724.2015.1023366In the new designs presented here, a cascoding technique is employed in the input stage. The simulation results presented below show significant improvements in performance of CMRR, power supply rejection ratio (PSRR), and bandwidth, as well as a desirable reduction in input referred offset voltage. 


\section{AN ESTABLISHED INPUT ARCHITECTURE}

For comparison purposes, the schematic circuit of an established CFOA architecture is shown in Fig.1. [20].

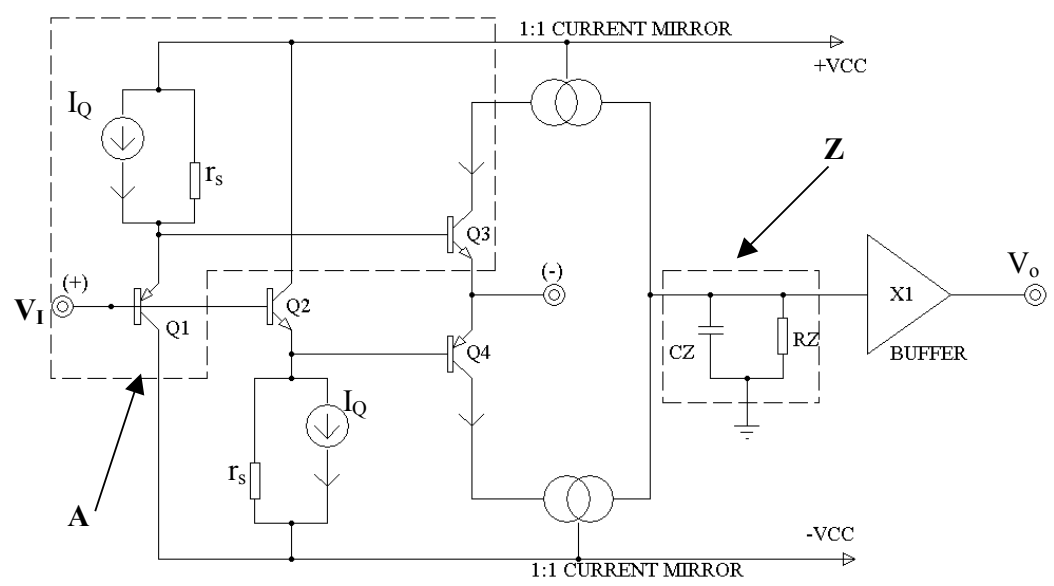

Figure 1. Schematic of an established CFOA architecture

For simplicity in a first-order analysis, the NPN and PNP transistors are assumed to have identical characteristics. Within the contour $A, Q_{1}$ together with its emitter load (bias current source $\mathrm{I}_{\mathrm{Q}}$ with output resistance $\mathrm{r}_{\mathrm{s}}$ ) and $\mathrm{Q}_{3}$ comprise an input 'half-circuit' and it is this halfcircuit concept that is explored further in this paper. The other half-circuit, comprising $\mathrm{Q}_{2}$ and its emitter load and $\mathrm{Q}_{3}$, behaves in an identical, complementary, manner. Consider, first, the CMRR, $\rho$. Fig. 2, in which diode $\mathrm{D}_{1}$ represents the base-emitter junction of $\mathrm{Q}_{1}$, shows an equivalent circuit for $\mathrm{A}$ when a common-mode input signal, $v_{\mathrm{cm}}$, is applied. As far as the change, $i$, in the collector current of $\mathrm{Q}_{3}$ is concerned, the circuit behaves like a 1:1 current mirror in which the effective rail supply is decreased in amount by $v_{\mathrm{cm}}$, so, $i$ comprises two components, viz, $-\left(v_{\mathrm{cm}} / \mathrm{r}_{\mathrm{s}}\right)$ due to the current change in $\mathrm{D}_{1}$ and $-\left(v_{\mathrm{cm}} / \mathrm{r}_{\mathrm{o}}\right)$ due to the change in collector emitter voltage across the common-emitter collector output resistance, $\mathrm{r}_{0}$, of $\mathrm{Q}_{3}$. Thus:

$i=-v_{c m}\left(\frac{1}{r_{s}}+\frac{1}{r_{o}}\right)$

This neglects the current change in the collector-base resistance, $r_{\mu}$, of $Q_{3}$, but since $r_{\mu}>>r_{o}$ [21], this is negligible. The common-mode current, $i_{\mathrm{cm}}$, flowing in load impedance $Z$, in Fig. 1, after being transmitted via the 1:1 current mirrors CM1, CM2 is double that given in equation 1 , because of the complementary action of $Q_{2}, Q_{4}$ Hence,

$$
g_{T c}=\left|\frac{i_{c m}}{v_{c m}}\right|=2\left(\frac{1}{r_{s}}+\frac{1}{r_{o}}\right)
$$


Fig. 3 shows the equivalent circuit for A when a differential-mode signal, $v_{\mathrm{dm}}$, is applied. Again, $i$ has two major components, one due to change in base-emitter voltage $\left(\cong v_{\mathrm{dm}}\right)$, and the other due to change in collector-emitter voltage of $\mathrm{Q}_{3}$

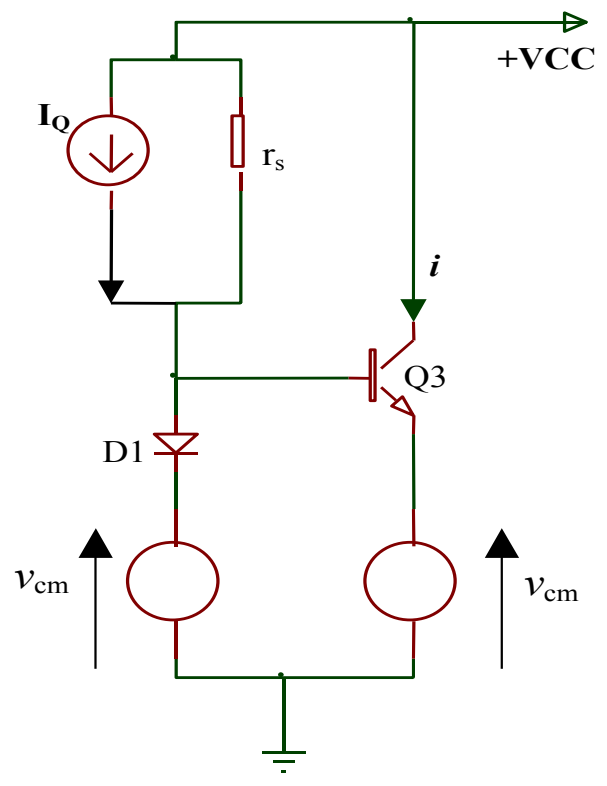

Figure 2. Representation of section A, for common mode signal $v_{\mathrm{cm}}$

$i \cong v_{d m}\left(g_{m}+\frac{1}{r_{o}}\right)$

In this equation $\mathrm{g}_{\mathrm{m}}$ (the transconductance of $\left.\mathrm{Q}_{3}\right)=\mathrm{I}_{\mathrm{Q}} / \mathrm{V}_{\mathrm{T}}$, with $\mathrm{V}_{\mathrm{T}}(=\mathrm{KT} / \mathrm{q})$ being the 'thermal voltage' ( $\approx 25 \mathrm{mV}$ at room temperature). As with $i_{\mathrm{cm}}, i_{\mathrm{dm}}$ is double that given by equation 3 . Given that $i_{\mathrm{dm}}$ is the differential-mode current.

$g_{T d}=\left|\frac{i_{d m}}{v_{d m}}\right| \approx 2\left(g_{m}+\frac{1}{r_{o}}\right) \approx 2 g_{m}$

The approximation is valid as $\mathrm{g}_{\mathrm{m}}>1 / \mathrm{r}_{\mathrm{o}}$ where, $\mathrm{r}_{\mathrm{o}}=\mathrm{V}_{\mathrm{A}} / \mathrm{I}_{\mathrm{Q}}, \mathrm{V}_{\mathrm{A}}\left(>>\mathrm{V}_{\mathrm{T}}\right)$ being the Early voltage. From equations 2 and 4;

$\rho=\frac{g_{T d}}{g_{T c}} \approx \frac{g_{m}}{\left(\frac{1}{r_{s}}+\frac{1}{r_{o}}\right)}$

For the special case $r_{s}=r_{0}$,

$\rho \approx \frac{V_{A}}{2 V_{T}}$ 
This equation is applicable when $\mathrm{I}_{\mathrm{Q}}$ is the output of a simple current mirror, as is meant to be the case for Fig. 1. Table 1 shows summaries of the variations of CMRR, $A_{d m}$ and $A_{c m}$ with changing values of $r_{\mathrm{ce} 1} ; r_{\mathrm{ce} 2} ; r_{\mathrm{e} 1}$, and $r_{\mathrm{e} 2}$.

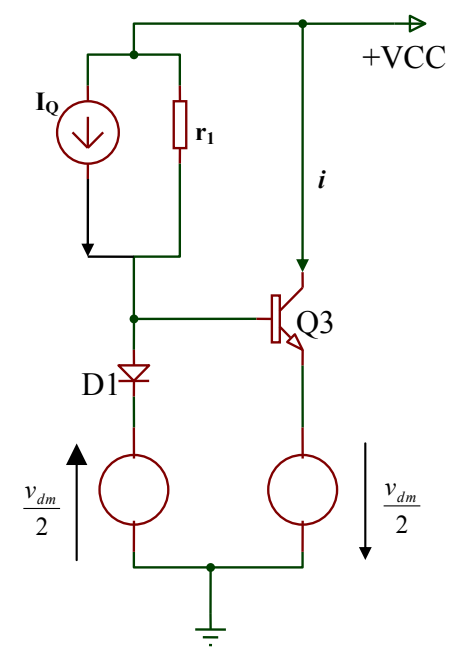

Figure 3. Representation of section A, for differential-mode signal $v_{\mathrm{dm}}$

To test this theoretical result, the full transistor level CFOA shown in Fig. 4 was simulated using SPICE. This was undertaken using Analog Devices XFCB device parameters. The variations of CMRR, $A_{d m}$ and $A_{c m}$ with changing values of $r_{c e 1}, r_{c e 2}, r_{e 1}$ and $r_{e 2}$ are listed in Table 1 . The obtained frequency responses of $A_{d m}, A_{c m}$ and CMRR are shown in Fig. 5. The values of the Early voltages $\mathrm{V}_{\mathrm{AP}}$ of the PNP devices $\mathrm{Q}_{7}$ and $\mathrm{Q}_{4}$, and $\mathrm{V}_{\mathrm{AN}}$ of the NPN device $\mathrm{Q}_{5}$ and $\mathrm{Q}_{3}$ were then doubled and the simulation repeated.

\begin{tabular}{|c|c|c|c|}
\hline Increase parameter & CMRR & $\mathrm{A}_{\mathrm{dm}}$ & $\mathrm{A}_{\mathrm{cm}}$ \\
\hline $\mathrm{r}_{\mathrm{ce} 1}$, and $\mathrm{r}_{\mathrm{ce} 2}$ & Increases & No change & Decreases \\
\hline $\mathrm{r}_{\mathrm{e} 1}$, and $\mathrm{r}_{\mathrm{e} 2}$ & Decreases & Decreases & No change \\
\hline
\end{tabular}

Table 1

These results are shown in Fig. 6. The results presented in Fig. 7 correspond to Early voltages of the input transistors four times greater than the actual AD-XFCB parameters. Although changing the values of $\mathrm{V}_{\mathrm{A}}$ in practice is virtually impossible, as a simulation exercise since $r_{c e} \approx V_{A} / I_{C Q}$, comparison of the results does confirm the anticipated significance of $r_{c e}$ in determining the CMRR of the CFOA.

In moving from Fig. 5 through to Fig. 7 , the values of $A_{c m}$ decreased as expected by $6 \mathrm{~dB}$, the values of $A_{d m}$ remained almost unchanged, and the CMRR increased by $6 \mathrm{~dB}$ for each step in doubling of $\mathrm{V}_{\mathrm{A}}$. Consider, next, the offset voltage, $\mathrm{V}_{\text {os }}$. This is the voltage at the emitter of $\mathrm{Q}_{3}$ when Fig. 1 is connected as a unity-gain follower $\left(V_{o}\right.$ connected to the inverting input), and $V_{I}$ is set to zero. Ideally, $\mathrm{V}_{\text {os }}=0$, but in reality $\mathrm{V}_{\text {os }}$ is finite $(\mathrm{a}$ few $\mathrm{mV}$ ) because of mismatch in the $\mathrm{V}_{\mathrm{BE}} \mathrm{S}$ of $\mathrm{Q}_{1}, \mathrm{Q}_{3}$. Finally, consider the SR. This, like $\mathrm{V}_{\mathrm{os}}$, is measured in the unity-gain configuration with a resistance (typically between $750 \Omega$ and $2 \mathrm{k} \Omega$ for $15 \mathrm{~V}$ rail supplies) [22] connected between $\mathrm{V}_{\mathrm{o}}$ and the inverting input, when a positive step voltage is applied at the non- 
inverting input. Transistors $\mathrm{Q}_{1}$ and $\mathrm{Q}_{4}$ (Fig. 1) tend to switch off and the SR is limited by the current, $\mathrm{I}_{\mathrm{Q}}$ available at the base of $\mathrm{Q}_{3}$.

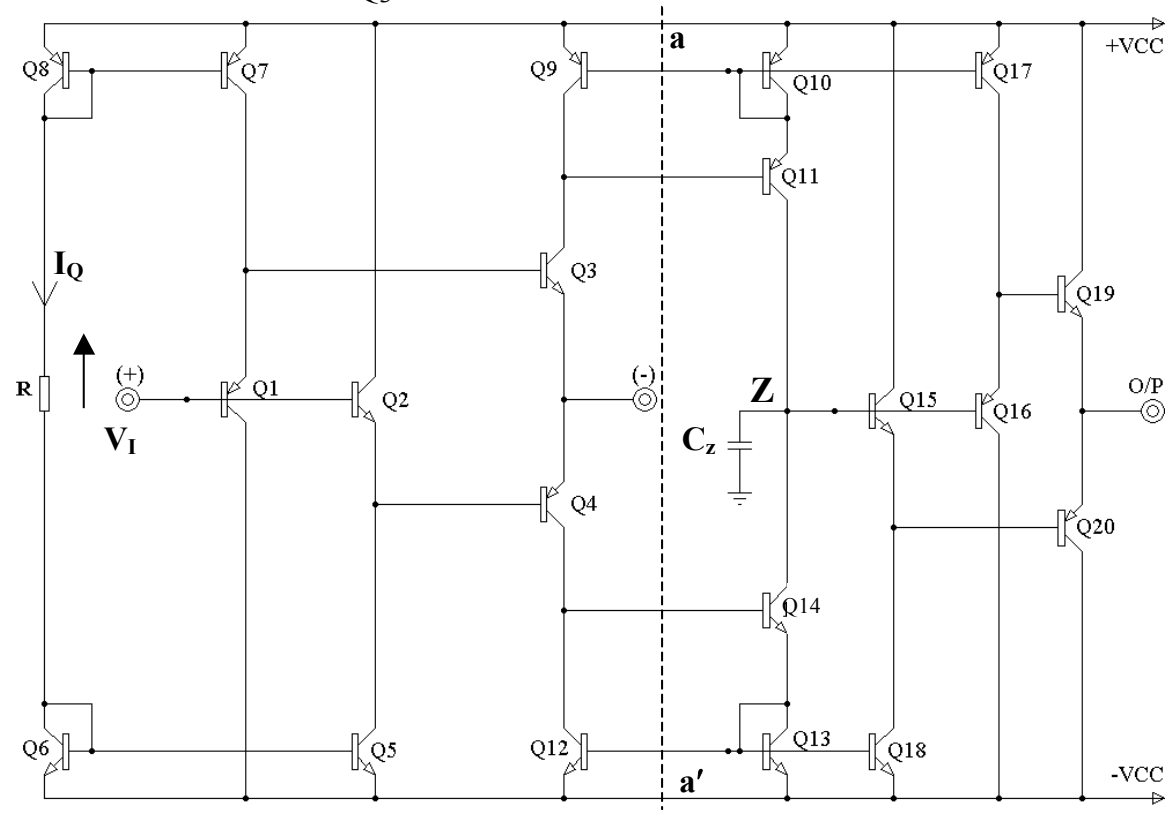

Figure 4. Circuit diagram of a basic CFOA

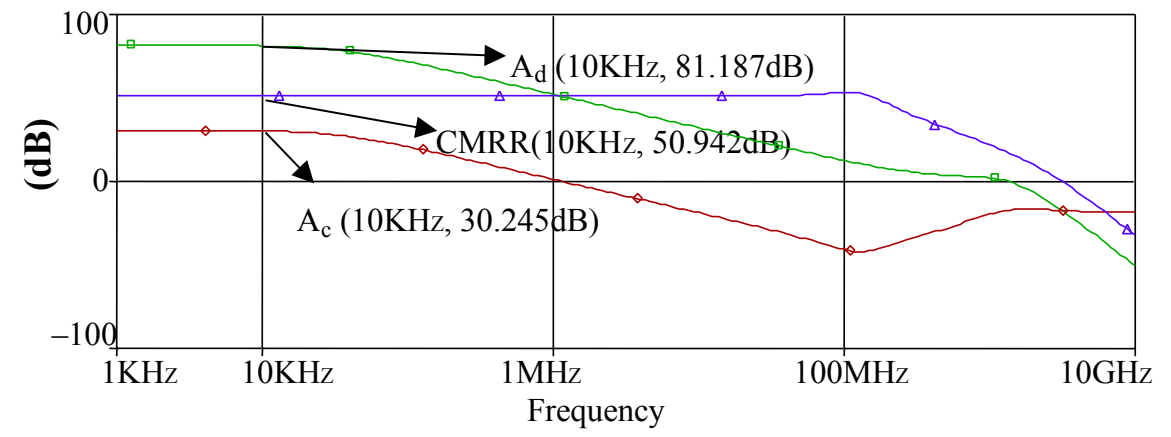

Figure 5. SPICE results for $A_{d m}, A_{c m}$ and CMRR versus frequency for Fig. 4 using $A D-X C F B$ process parameters.

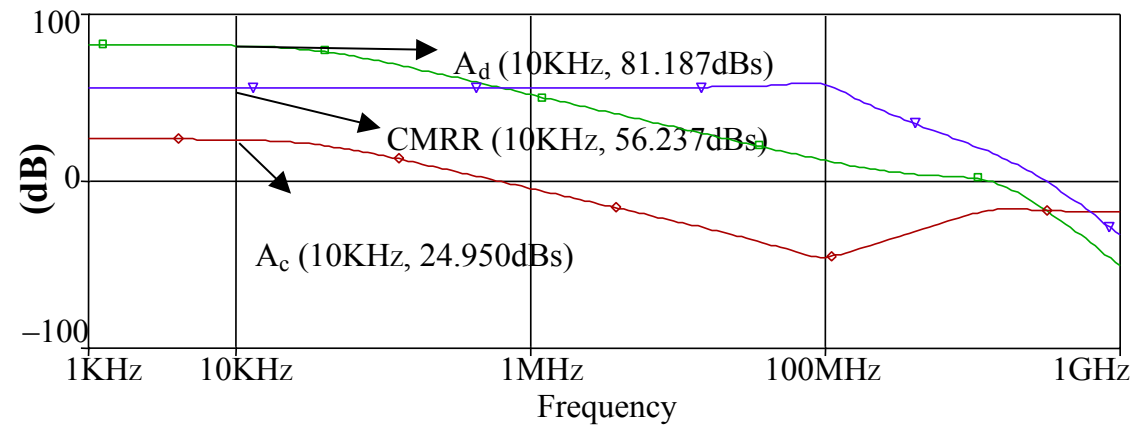

Figure 6. $A_{d m}, A_{c m}$ and CMRR versus frequency, as in Fig. 5, except that $V_{A}$ has been doubled for the input stage devices. 


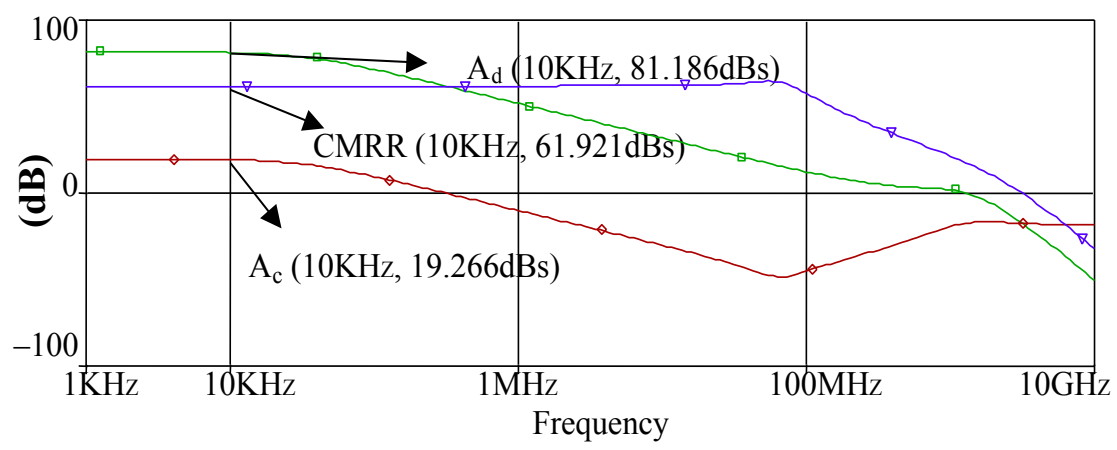

Figure 7. $A_{d m}, A_{c m}$ and CMRR versus frequency, as in Fig. 6 except that $V_{A}$ has been quadrupled for the input stage devices.

\section{Quiescent power dissipation}

The quiescent power dissipation for any amplifier circuit is a characteristic, which designers usually try to minimize. It is apparent from Fig.4 that there are eight conduction paths, from $+\mathrm{V}_{\mathrm{CC}}$ power supply to the $-\mathrm{V}_{\mathrm{CC}}$ power supply, each passing a quiescent current $\mathrm{I}_{\mathrm{Q}}$, defined by $\mathrm{R}$, $+\mathrm{V}_{\mathrm{CC}},-\mathrm{V}_{\mathrm{CC}}$.

The quiescent power dissipation $\mathrm{P}_{\mathrm{Q}}$ is this given by

$P_{Q}=2 V_{C C} \times 8 I_{Q}=16 V_{C C} I_{Q}$

where,

$I_{Q}=\left(\frac{2 V_{C C}-2\left|V_{B E}\right|}{R}\right)$

Alternatively, we can write,

$P_{Q}=16 V_{C C}\left(\frac{2 V_{C C}-2 V_{D}}{R}\right)$

\section{CFOA with cascoding}

Fig. 8 shows the proposed Cascode CFOA design. The box, A, encloses a cascode current mirror which is replicated three times, in NPN form, in the input stage. A similar PNP cascode current mirror also replicated three times in the design. The output stage of the CFOA is a class-AB complementary pair. The mirror-symmetry of the input stage about an imaginary horizontal line joining the '+', and '-' inputs guarantees a low offset voltage. The cascode transistors $\mathrm{Q}_{15}, \mathrm{Q}_{16}$ increase the effective collector output resistances of $\mathrm{Q}_{3}, \mathrm{Q}_{4}$, respectively. 


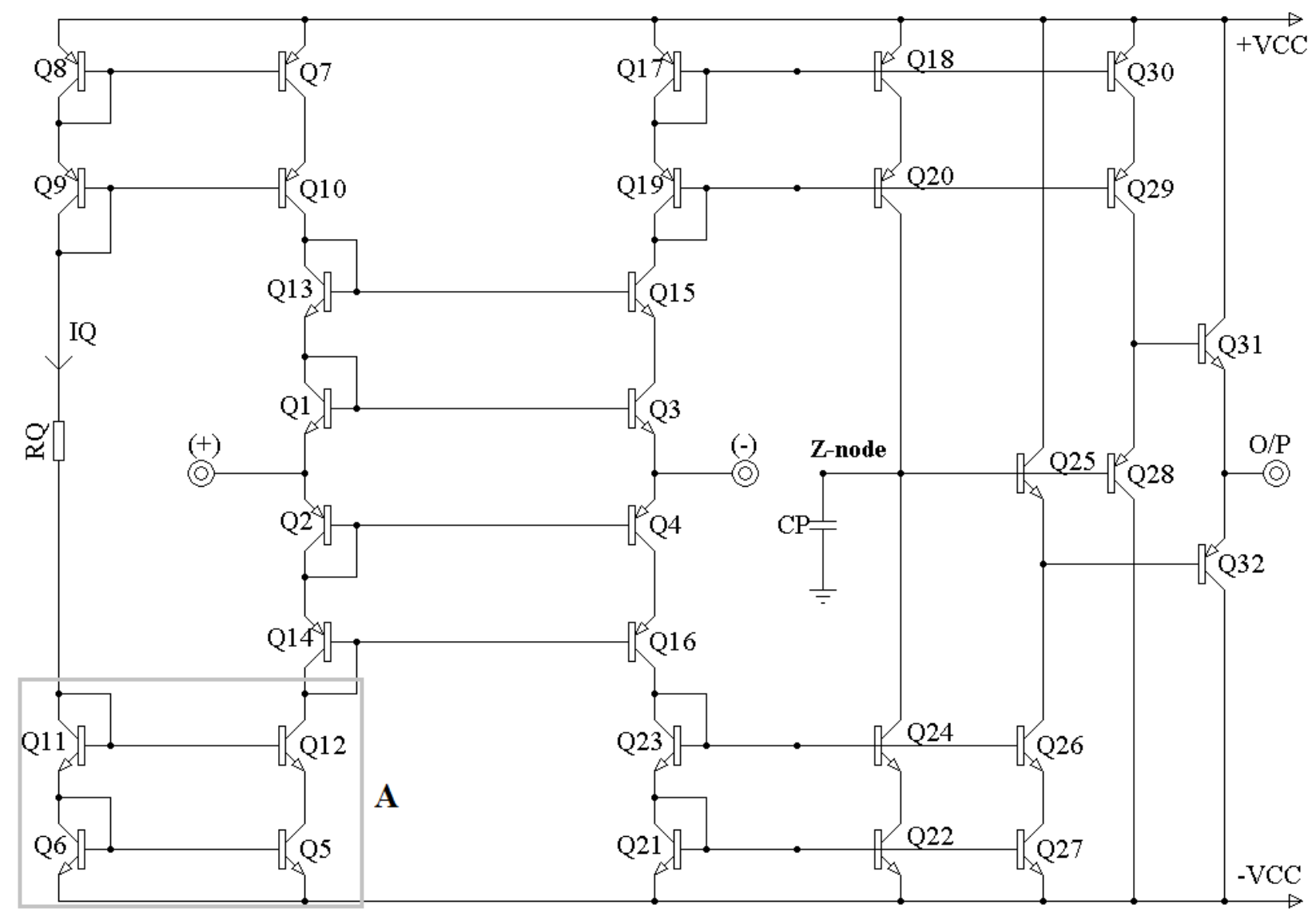

Figure 8. A CFOA with Cascoding

\section{CFOA with forward and reverse-bootstrapping}

A bipolar-transistor CFOA based on an alternative cascode scheme is shown in Fig.9, and should be compared with the Cascode CFOA shown in Fig.8. Fig. 9 shows an improved CFOA with a novel input stage that utilises both forward and reverse boot-strapping to achieve the desired effect of increasing significantly the CMRR.

In Fig. 9, the Cascode Current-mirrors [21], $\left(\mathrm{Q}_{7}+\mathrm{Q}_{8}+\mathrm{Q}_{13}+\mathrm{Q}_{14}+\mathrm{Q}_{26}+\mathrm{Q}_{35}\right)$ and $\left(\mathrm{Q}_{5}+\mathrm{Q}_{6}+\mathrm{Q}_{15}+\mathrm{Q}_{16}+\mathrm{Q}_{25}+\mathrm{Q}_{36}\right)$ are supplied with a common input current, $\mathrm{I}_{\mathrm{Q}}$, via the resistor $\mathrm{R}_{\mathrm{Q}}$. Since the action of the two buffered-mirrors is the same, only one is considered here, $\left(\mathrm{Q}_{7}+\mathrm{Q}_{8}+\mathrm{Q}_{13}+\mathrm{Q}_{14}+\mathrm{Q}_{26}+\mathrm{Q}_{35}\right), \mathrm{Q}_{17}$, with its base bias provided by the diode-connected transistors $\mathrm{Q}_{19}, \mathrm{Q}_{21}$ and $\mathrm{Q}_{23}$, increases the output resistance of the $\mathrm{Q}_{14}$ cascode current source, and in the same way $\mathrm{Q}_{18}$ cascodes $\mathrm{Q}_{16}$ and increases the output resistance of $\mathrm{Q}_{16}$. The input transistors $\mathrm{Q}_{1}$ and $\mathrm{Q}_{2}$ are cascoded by $\mathrm{Q}_{9}$ and $\mathrm{Q}_{11}$ respectively.

This novel input circuit topology gives higher CMRR, and lower DC offset voltage because the use of both casoding and boot-strapping results in a significant decrease in the common-mode currents within the input stage. 


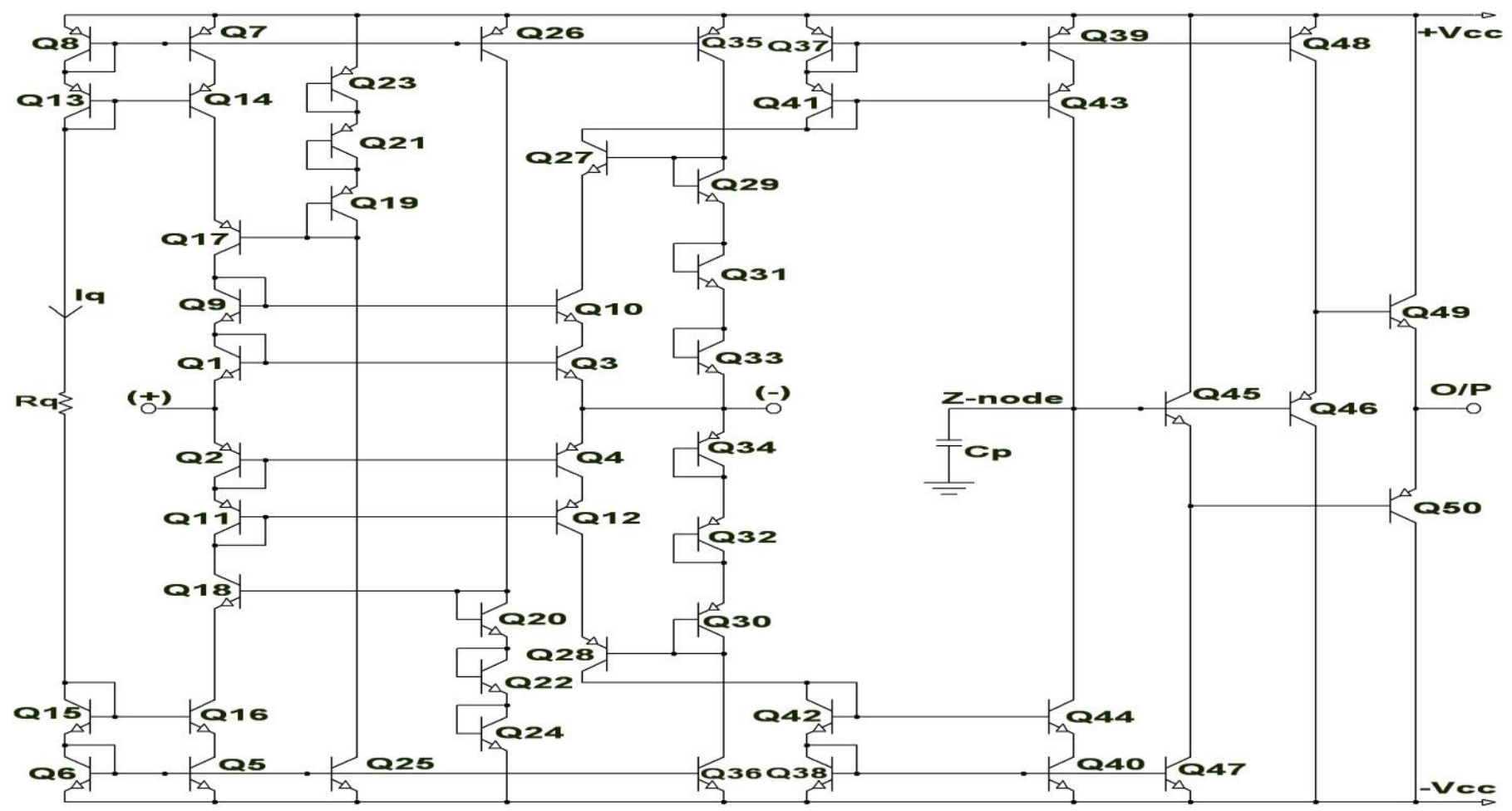

Figure 9. Circuit diagram of a CFOA using Forward and Reverse-Bootstrapping

\section{Simulation results}

OrCAD PSpice was used to verify the operation and performance of the circuits. The technology used in the simulation was the complementary bipolar XFCB process of Analog Devices, Santa Clara, California (see Acknowledgements).

The power supply voltages were set to $\pm 4.5 \mathrm{~V}$. For comparative assessment three CFOAs were simulated, namely, (i) a conventional CFOA [23] (ii) the Cascode CFOA shown in Fig.8, and (iii) the Forward and Reverse Bootstrapping CFOA shown in Fig.9. All three were simulated with the same technology parameters, and were set to operate at a bias current, $\mathrm{I}_{\mathrm{Q}}$, equal to $0.50 \mathrm{~mA}$. A list of the simulated characteristics of both improved CFOAs, and conventional CFOA is given Table .2. The CMRR in both the Cascode CFOA, and the Forward and Reverse Bootstrapping CFOA have been increased, to about $80.1 \mathrm{~dB}$, and $90.5 \mathrm{~dB}$ respectively, whilst in the conventional CFOA it remains at about $50.4 \mathrm{~dB}$. Fig .10 gives the PSpice simulation of the CMRR vs. frequency characteristic for the three CFOAs. A substantial improvement in the CMRR has thus been achieved.

Fig. 11 shows that the overall AC gain accuracy for the Cascode CFOA is given as $800 \mu \mathrm{V}$, compared to $5.9 \mathrm{mV}$ for the conventional $\mathrm{CFOA}$ and $6.2 \mathrm{mV}$ for the Forward and ReverseBootstrapping CFOA. For the Forward and Reverse Bootstrapping CFOA the bandwidth was $69 \mathrm{MHz}$, and for the Cascode CFOA and the conventional CFOA was $65.6 \mathrm{MHz}$, and $52.3 \mathrm{MHz}$ respectively as shown in Fig 12. The transient results for the three CFOAs, driving a $10 \mathrm{~K} \Omega$ load resistance, are shown in Fig 13, and Table 2. The non-inverting impedances of the three CFOAs were determined, and the results are in line with the expected values for a differential signal, Fig 
14, and Table 2. Fig 15 shows the inverting input impedance response versus the frequency for the three CFOAs. Table 2 shows that the DC offset voltage was reduced dramatically in both the Cascode CFOA, and the Forward and Reverse-Bootstrapping CFOA to $\pm 166 \mathrm{mV}$, and $\pm 5.1 \mathrm{mV}$, respectively; compared with the much larger $\pm 12.5 \mathrm{mV}$ of the conventional CFOA.

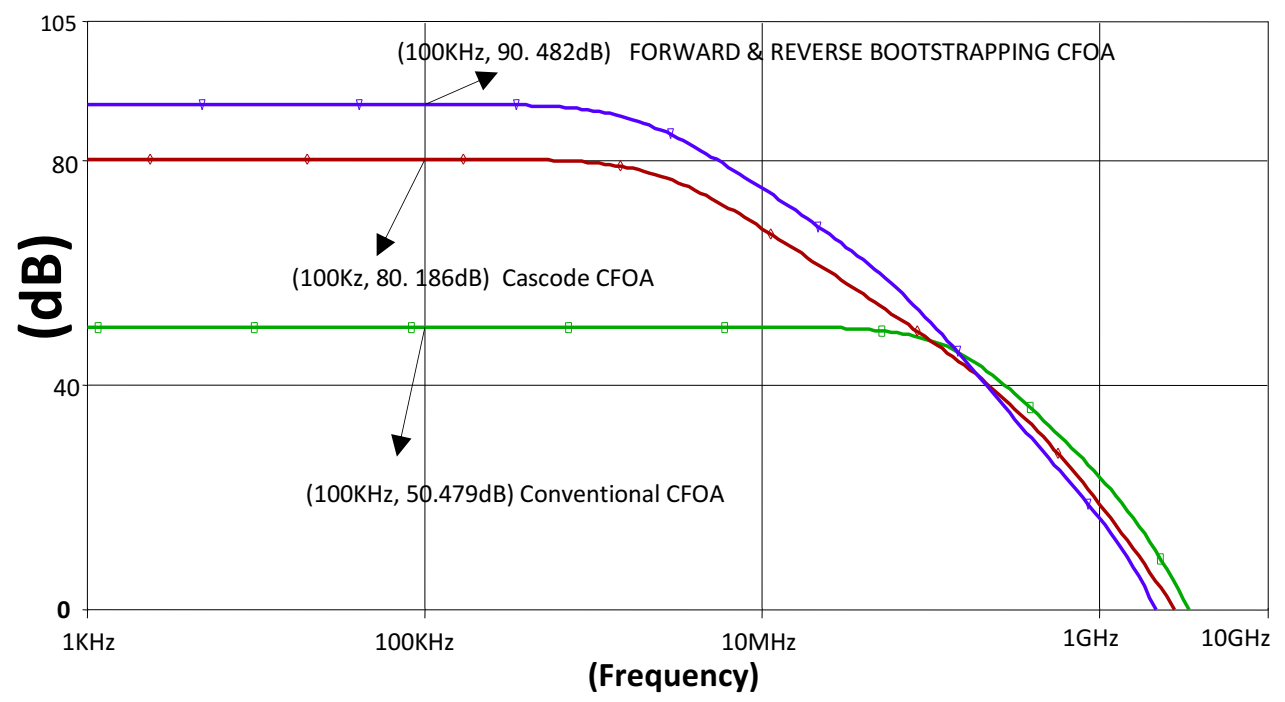

Figure 10. CMRR Frequency, comparisons

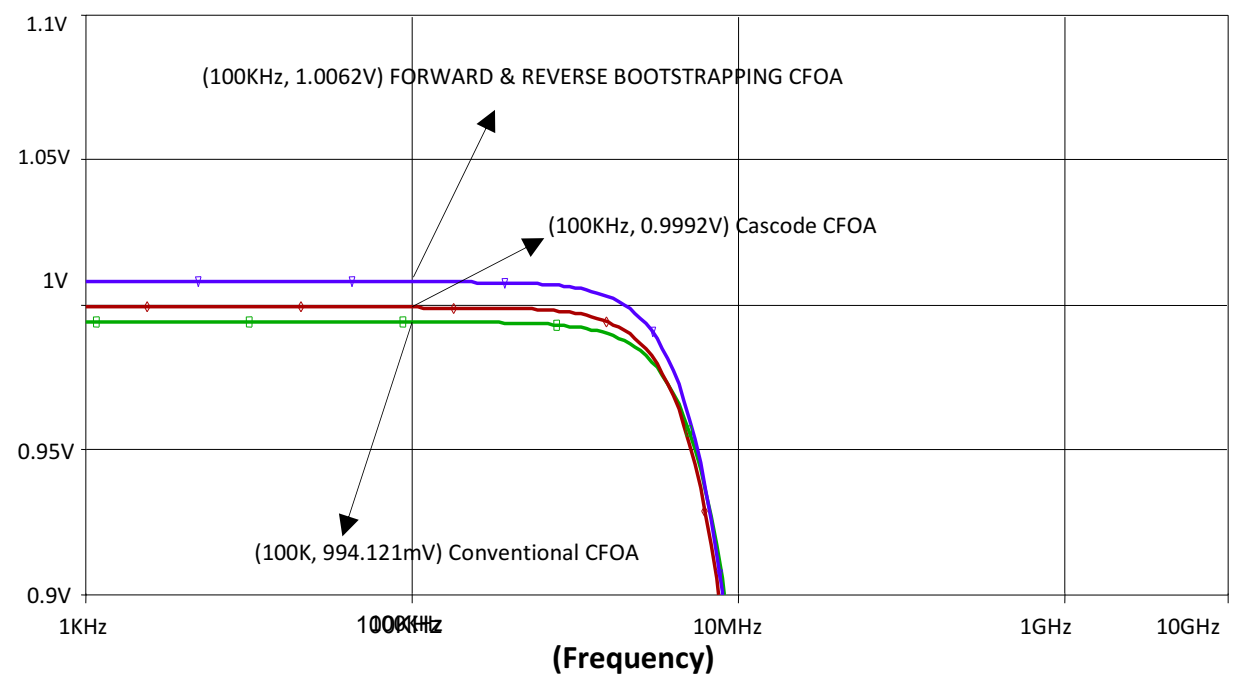

Figure 11. AC gain accuracy $\sim$ Frequency, comparisons 


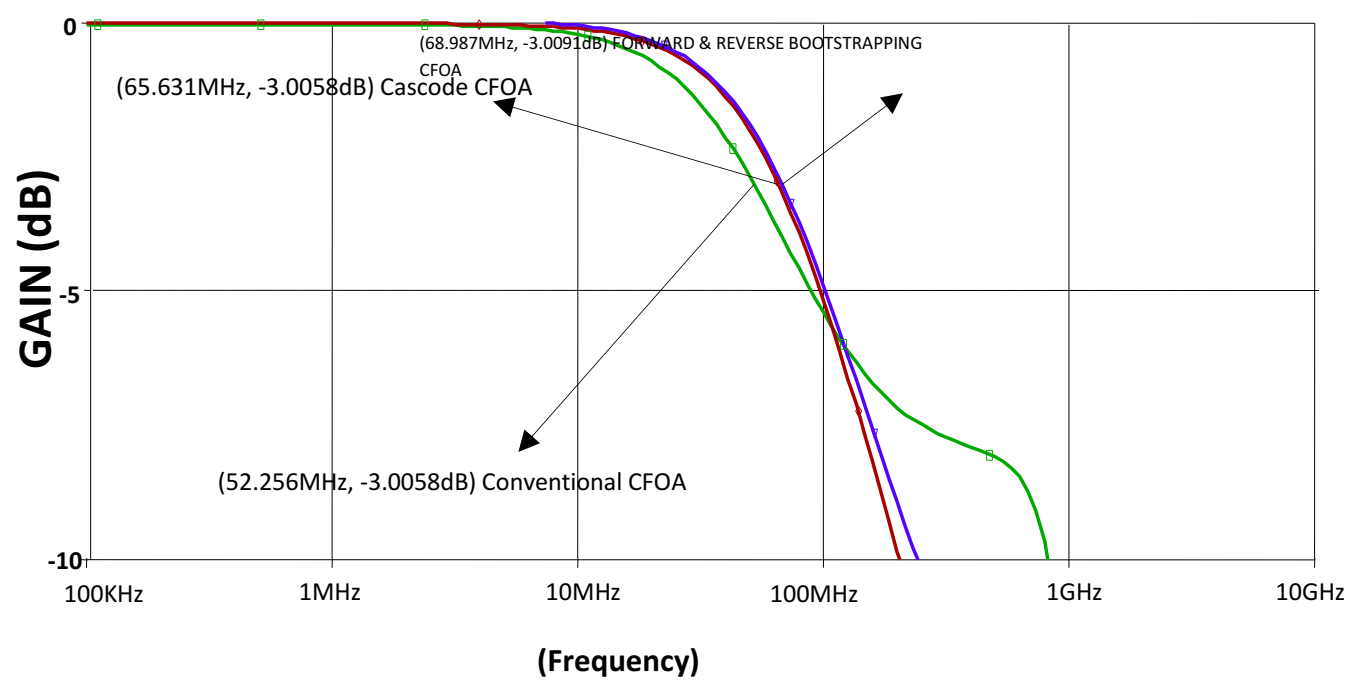

Figure 12. Frequency responses for unity closed-loop gain comparisons

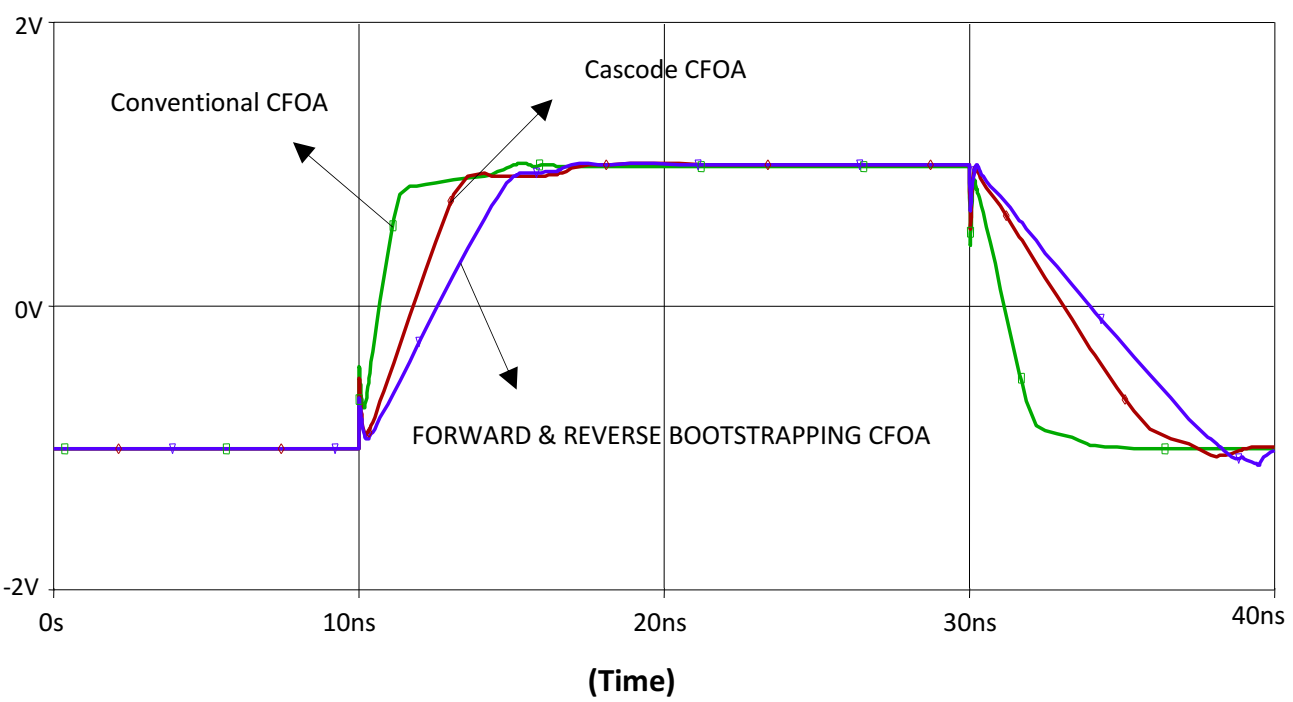

Figure 13. Slew Rate comparisons 


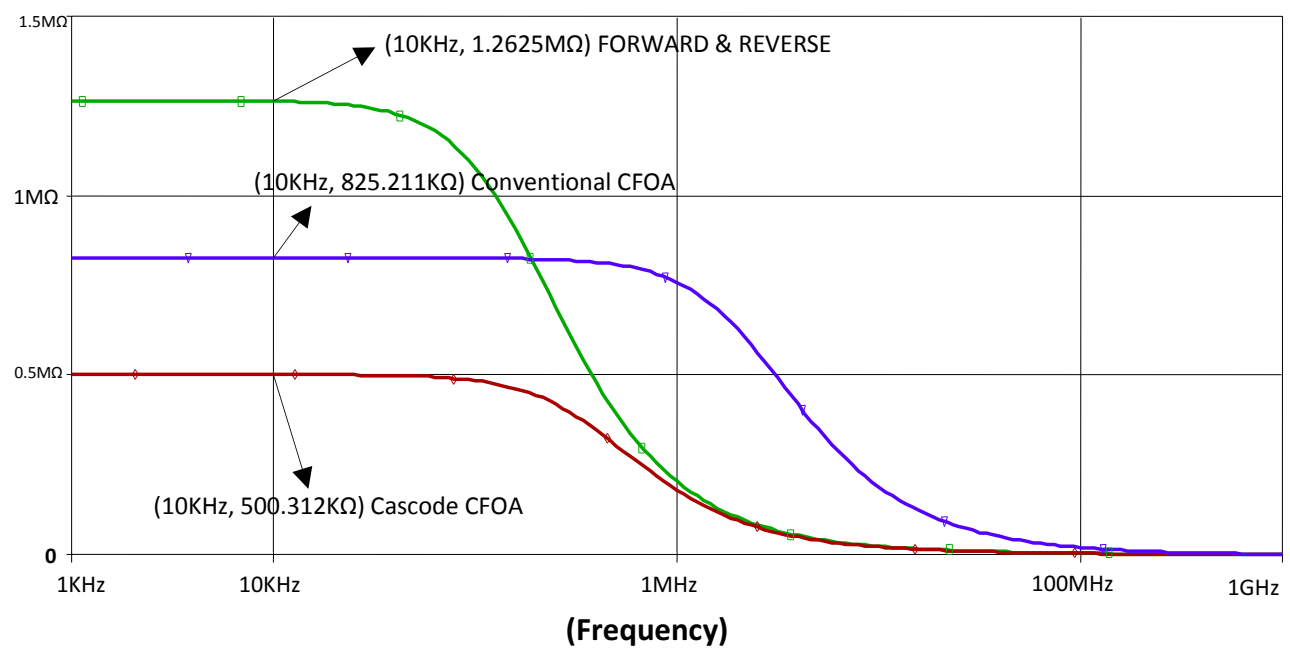

Figure 14. Input impedance frequency, comparisons for the CFOAs, each configured as a noninverting unity gain amplifier

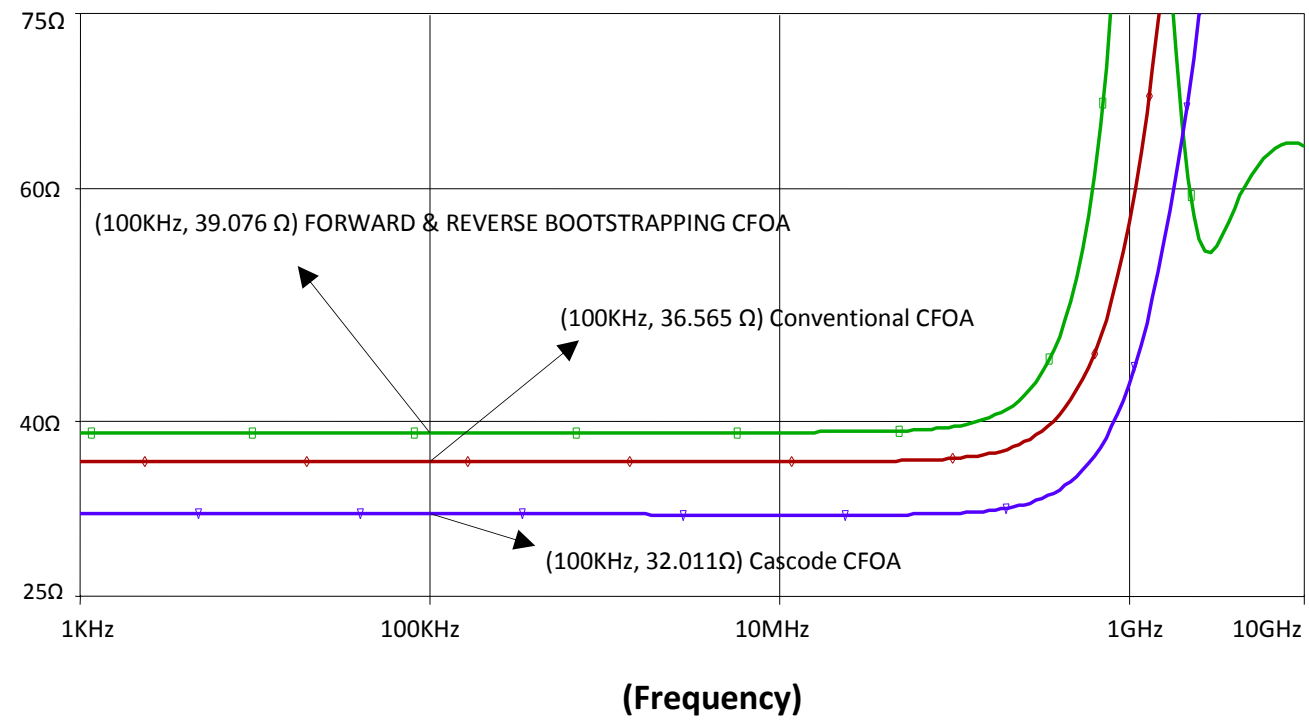

Figure 15. Input Resistances (inverting) Frequency comparisons 


\begin{tabular}{|l|c|c|c|}
\hline & $\begin{array}{c}\text { CONVENTIONAL CFOA } \\
\text { (Fig .4) }\end{array}$ & CASCODE CFOA (Fig .8) & $\begin{array}{c}\text { FORWARD \& REVERSE } \\
\text { BOOTSTRAPPING CFOA } \\
\text { (Fig 9) }\end{array}$ \\
\hline CMRR & $50.5 \mathrm{~dB}$ & $80.2 \mathrm{~dB}$ & $90.5 \mathrm{~dB}$ \\
\hline Bandwidth & $52.3 \mathrm{MHz}$ & $65.6 \mathrm{MHz}$ & $69 \mathrm{MHz}$ \\
\hline $\begin{array}{l}\text { Inverting input } \\
\text { resistance (at 0V d.c. } \\
\text { input) }\end{array}$ & $36.6 \Omega$ & $32 \Omega$ & $1.1 \Omega$ \\
\hline $\begin{array}{l}\text { Non-inverting buffer } \\
\text { input resistance (at } \\
\text { 0V d.c. input) }\end{array}$ & $825.2 \mathrm{~K} \Omega$ & $500.3 \mathrm{~K} \Omega$ & \\
\hline $\begin{array}{l}\text { AC gain error (Unity } \\
\text { gain, Vin = 1V pp) }\end{array}$ & $5.9 \mathrm{mV}$ & $800 \mu \mathrm{V}$ & $6.2 \mathrm{mV}$ \\
\hline $\begin{array}{l}\text { Input offset voltage } \\
\text { (at 0V d.c. input) }\end{array}$ & $\pm 12.3 \mathrm{mV}$ & $\pm 166 \mu \mathrm{V}$ & $\pm 5.1 \mathrm{mV}$ \\
\hline Slew rates & $\begin{array}{l}\mathrm{SR}+=1351 \mathrm{~V} / \mu \mathrm{s} \\
\mathrm{SR}-=965.6 \mathrm{~V} / \mu \mathrm{s}\end{array}$ & $\begin{array}{l}\mathrm{SR}+=650.1 \mathrm{~V} / \mu \mathrm{s} \\
\mathrm{SR}-=360.3 \mathrm{~V} / \mu \mathrm{s}\end{array}$ & $\begin{array}{l}\mathrm{SR}+=460.4 \mathrm{~V} / \mu \mathrm{s} \\
\mathrm{SR}-=290.2 \mathrm{~V} / \mu \mathrm{s}\end{array}$ \\
\hline
\end{tabular}

Table 2

\section{Conclusions and future work}

Analysis of the conventional CFOA has provided a deeper understanding of the internal operation of the circuit, and this work revealed that the shortcomings in CMRR, input referred offset voltage and gain accuracy of the CFOA are in the design of the input stage. This part of the amplifier is responsible for the poor CMRR performance compared with that of a voltagemode op-amp. Using the initial analysis of the conventional CFOA as a benchmark, two new CFOAs with improved performances have been designed and developed. Both of these new CFOAs have a high CMRR with an acceptably high SR. The benefits of greater accuracy, reduced DC offset voltage, together with an architecture that has a high CMRR, and acceptable bandwidth (of about $69 \mathrm{MHz}$ ) make these CFOAs a welcome and useful addition to the analogue designer's tool kit.

However, the price paid for these improvements is a reduced output voltage swing for given rail voltages, because of vertical transistor stacking. Clearly, the new CFOAs do use more transistors but the performance advantages particularly in terms of CMRR improvement justify the increased complexity when this parameter is of paramount interest. The primary disadvantage are the moderately high power supply voltages required. The authors are currently modifying the design to reduce the power supply voltage requirements by replacing the conventional cascode circuits with folded-cascodes.

Bipolar technology CFOA offer high-speed, high-bandwidth, high-slewing amplifier with lowfrequency noise performance at low quiescent currents. Moreover, bipolar transistors inherently offer better matching, resulting in lower offset voltages than CMOS for any given architecture. However, if the op amp interfaces with a high-impedance sensor, such as a thermocouple with some passive filtering, then keeping bias currents to a minimum will be important and CMOS is a better technology to choose. 
This work is on-going, and the authors anticipate being able to report new CFOAs using CMOS technologies and BiCMOS hybrid technology, the latter taking the best from both worlds and providing superior performance at a price point that is becoming more competitive.

\section{Acknowledgements}

The authors gratefully acknowledge Analog Devices, Santa Clara, California, for providing device model data for the transistors used in the design. They also thank Dr. Bryan Hart for his useful suggestions and advice.

\section{References}

[1] A. Tammam, K Hayatleh, B Hart and F J Lidgey, 'High Performance Current-Feedback OpAmps', Proceeding of the International Symposium on circuits and systems, Vancouver, British Columbia, Canada, 2004.

[2] S. Wenjun, 'Design and development of high CMRR wide bandwidth instrumentation Amplifiers', PhD thesis, Oxford Brookes University, 1997, pp. 93-118.

[3] Graeme J.G, Tobey G.E, Huelsman L.P, 'Operational amplifier design and applications', Burr-Brown Research Corporation, USA, 1971, pp.xvii.

[4] C. Toumazou, A. Payne, F. J. Lidgey, 'Current-feedback versus voltage feedback amplifiers: history, insight and relationships', IEEE Int Symp Circuits Syst 2:1046-1049, 1993.

[5] K. C. Smith, A, Sedra, 'The current conveyor-a new circuit building block', Proc IEEE 56:1368-1369, 1968.

[6] S. A. Mahmoud, H. O. Elwan, A. M. Soliman, 'Low voltage rail to rail CMOS current feedback operational amplifier and its applications for analog VLSI', Analog Integr Circ Sign Process 25:47-57, 2000.

[7] J. G. S. Gift, B. Maundy, 'Improving the bandwidth gain-independence and accuracy of the current feedback amplifier', IEEE Trans Circ Syst-II 52(3):136-139, 2005.

[8] S. Pennisi, G. Scotti, A. Trifiletti,'Avoiding the gain-bandwidth trade off in feedback amplifiers', IEEE Trans Circ Syst-I 58(9):2108-2113, 2011.

[9] B. Maundy, S. Gift, S. Magierowski, 'Constant bandwidth current feedback amplifier from two operational amplifiers', Int J Electron 94: 605-615, 2007.

[10] Wong J, 'Current-feedback op-amps extend high-frequency performance', EDN, October 26, 1989, pp.211-216.

[11] Ananda Mohan PV, 'Comments on avoiding the gain-bandwidth trade off in feedback amplifiers', IEEE Trans Circ Syst-I 58(9): 2114-2116, 2011.

[12] A. H. Madian, S. A. Mahmoud, A. M. Soliman, 'Configurable analog block based on CFOA and its application', WSEAS Trans Electron 5:220-225, 2008.

[13] B. Maundy, S. J. G Gift, P. B. Aronhime, 'A novel differential high-frequency CFA integrator’, IEEE Trans Circ Syst-II 51:289-293, 2004.

[14] E. Yuce, S. Minaei, 'A modified CFOA and its applications to simulated inductors, capacitance multipliers, and analog filters', IEEE Trans Circ Syst-I 55(2): 266-275, 2008.

[15] B. Harvey, 'Current feedback op amp limitations: a state-of-the-art review', IEEE Int Symp Circ Syst 2:1066-1069, 1993.

[16] K. Koli, K. Halonen, 'CMRR Enhancement Techniques for Current-Mode Instrumentation Amplifiers', IEEE Trans. Circuits and Systems-I, vol. CAS-47, May 2000, pp. 622-632.

[17] J. T. Li, S. H. Pun, M. I. Vai, P. U. Mak, P. I. Mak, and F. Wan, 'Design of current mode 
instrumentation amplifier for portable biosignal acquisition system', Proc. IEEE Biomed. Circuits Syst. Conf., Nov. 2009, pp. 9-12.

[18] S. S. Bustos and J. S. Martinez, 'Design Considerations for Biomedical Signal Interfaces', IEEE MMICA'99, pp. 187-191, 1999.

[19] C. T. Ma, P. I. Mak, M. I. Vai, P. U. Mak, S. H. Pun, F. Wan and R. P. Martins, 'A 90nm CMOS Bio-Potential Signal Readout Front-End with Improved Powerline Interference Rejection', in Proc. IEEE ISCAS 2009, pp. 665-668, May 2009.

[20] S. Franco, 'Design with Operational Amplifiers and Analog Ics', Mc Graw Hill, 3 rd edition, Chapter 6, p. 294, 2002.

[21] P. R. Gray, and R. G. Meyer, 'Analysis and Design of Analog Integrated Circuits', New York: Wiley, $3^{\text {rd }}$ Edition, pp. 36-37, 1993.

[22] F. J. Lidgey, and K. Hayatleh, 'Current-Feedback Operational Amplifiers and Applications', IEE Journal on Electronics and Communications, pp. 176-181, August 1997.

[23] C. Toumazous, F.J. Lidgey, and D. Haigh, 'Analog IC design: the current-mode approach', (IEE Circuits and Systems series, Peter Peregrinus, 1990), Chap. 4, pp. 164. 